\title{
Adsoprtion Characteristic of Fancy Veneer Overlaid Charcoal Board Composite*1
}

\author{
Seog Goo Kang ${ }^{* 2}$ and Hwa Hyoung Lee ${ }^{* 2 \dagger}$
}

\begin{abstract}
This study was carried out to manufacture very thin natural elm veneer overlaid charcoal board for enhancing aesthetic value of charcoal board for the indoor application, and to use the advantageous properties of the charcoal as a building material for solving the sick house problem. The thin elm veneer had $26.9 \%$ opening ratio. The experiment results showed that the spreading area and the nonvolatile content of adhesive did not affect the gas adsoprtion of fancy veneer overlaid charcoal board. The natural thin elm veneer overlaid charcoal board enhanced not only the aesthetic beauty but also showed the same gas adsorption by the charcoal board.
\end{abstract}

Keywords : thin natural veneer, elm, charcoal board, gas adsorption, overlaid

\section{INTRODUCTION}

Charcoal is the black residue consisting of mainly impure carbon obtained by removing water and other volatile constituents from animal and vegetation substances. Charcoal is usually produced by slow pyrolysis, the heating of wood or other substances in the absence of oxygen. The resulting soft, brittle, lightweight, black, and porous material resembles coal and is composed of $50 \%$ to $95 \%$ carbon with the remaindersof volatile chemicals and ash. Black charcoal which is soft and easy to ignite at temperatures between $250 \sim 450^{\circ} \mathrm{C}$ is carbonized at temperatures between 400 and $700^{\circ} \mathrm{C}$, then the kiln is sealed until the burning stops and the heat slowly dies away. On the other hand, white charcoal is made by carbonizing the wood at a moderately low temperature, then, near the end of the process, the kiln temperature is raised up to approximately $1,000^{\circ} \mathrm{C}$ to make the wood red hot. When the charcoal have turned deep red, the charcoal is removed from the kiln and quickly smother it with a covering of a powder mixture of sand, earth, and ash to cool it. This will then give a whitish color to the surface of the charcoal, where the name "white charcoal" was derived from. The ignition temperature of white charcoal is $350 \sim 520^{\circ} \mathrm{C}$. Generally, the higher carbonization temperature charcoal has,

*1 Received on March 2, 2010; accepted on April 13, 2010

*2 Department of Biobased Materials, College of Agriculture \& Life Science, Chungnam National University, Daejeon 305-764, Korea

† Corresponding author : Hwa Hyoung Lee (e-mail: hhlee@cnu.ac.kr) 
the higher ignition temperature it has. The higher remainders of volatile chemicals charcoal has, the lower ignition temperature it has (Shin et al., 1983). An increase of $\mathrm{C}$ content as well as decrease of $\mathrm{H}$ content were observed up to about $600{ }^{\circ} \mathrm{C}$ with increasing the carbonization temperature and the ratio changes of the atoms became stable at above $600^{\circ} \mathrm{C}$ (Jo et al., 2009; M. Krzesinska 2007). Recently, charcoal attracted a lot of attention not only by their environmentally friendliness but also by their unique functional characteristics, such as catalysis, moisture absorption, soil conditioning, filtering, deodorization, purification, far-infra red emission, and electromagnetic shielding effects (Kong and Kim, 2002; Jo, Ahn, and Choi, 2005; Lee et al., 2005; Jo, et al., 2009; Lee and Kim, 2002; Kim and Lee, 2006; Shin and Kim, 2006; Wang and Hung, 2003). Charcoal could be activated to increase its effectiveness as a filter. Activated charcoal readily adsorbs a wide range of organic compounds dissolved or suspended in gases and liquids. Charcoal is often used to filter moisture or water to remove bacteria and undesired tastes. Historically, charcoal was used in great quantities for industrial fuel. Charcoal was consumed in the past as dietary supplement for gastric problems in the form of charcoal biscuits. Now it can be consumed in tablet, capsule or powder form for the digestive benefits. Charcoal absorbs gases and toxins to help heartburn, flatulence or indigestion (Rolland, 2006; Braithwaite, 1856).

Indoor air quality could affect health and comfort of building occupants, who are increasingly interested in home air purification because of a lot of pollutants of indoor air quality and sick house syndrome. Moreover, recent findings have demonstrated that indoor air is often more polluted than outdoor air. Basket and container filled with a lot of lump of charcoal were placed beside television and computer, in the wardrobe, and in the shoe closet for the health and indoor air quality, but these are not good for the respects of aesthetic beauty and efficiency. Reclamation of charcoal under the building site gives higher electric potential, higher anion emission, and better environment condition for human body such as the inhibition of oxidization, air purification, gas adsoprtion, humidity control and far-infra red emission. Recently, non-woven fabric sack filled with charcoal powder is placed under floor and living room, and non-woven fabric sheet with charcoal powder is installed in the wall for removing toxic gas and smell. Especially, volatile organic compounds and formaldehyde are regulated in indoor air environment. Since people spend most of their time today at home or in an office, long-term exposure to VOCs in the indoor environment can contribute to sick building syndrome. Many building materials such as paints, adhesives, wall boards, and ceiling tiles emit formaldehyde, can occur to the mucous membranes and can make a person irritated and uncomfortable. There are also many sources of VOCs in office buildings, which include new furnishings, wall coverings, and office equipments such as photocopy machines which can emit VOCs into the air. ${ }^{『}$ The indoor air quality control law of multiplex use facility etc. $₫$ has been revised and enforced from on May $30^{\text {th }}, 2004$. Proposition of this indoor air quality control law which has concerned introducing a quality-certification process of the wood panel products for the production, imports, circulation and the use (Article 13 and Article 14) has given lawmaking notice on May, 2009 and this law will be put into force from 2012.

Lee et al. (2004, 2005, 2006) has attempted to use the advantage properties of charcoal board for promoting a pleasant residential environment through the improving indoor air quality. Lee developed the new method not only 
for making the charcoal board and charcoal board composite with excellent properties such as dimensional safety, gas adsoprtion, and far-infra red emission for building interior material, but also for manufacturing functional black charcoal board with excellent working properties from municipal wood waste. Park et al. (2009) also invented manufacturing techniques of crack-free carbonized board from fiberboard. But the color of charcoal board is black and black wall and ceiling with charcoal board plunge home into darkness. The whole black wall does not suit with the sense of the aesthetic beauty. Black color needs to be improved.

The aim of this study was to investigate whether gas passes through the very thin natural elm veneer-adhesive composite layer to the base of charcoal board or not.

This experiment carried out to show that the natural thin elm veneer overlaid charcoal board enhance the aesthetic beauty and the spreading area as well, and that the nonvolatile content of adhesive do not affect the gas adsoprtion of fancy veneer overlaid charcoal board.

\section{MATERIALS and METHODS}

\subsection{Materials}

\subsubsection{Charcoal and Veneer}

White charcoal of Quercus variabilis BI. was reduced to powder with the ratio of $\# 6 \sim 12$ (7\%), \#12 18 (14\%), \#18 40 (43\%), \#40 60 (23\%), \#60 100 (9\%), and below \#100 (4\%). Thin elm veneer of $0.22 \mathrm{~mm}$ thickness was used for the decoration of charcoal board.

\subsubsection{Adhesive}

Polyvinyl acetate resin (PVA, NVC 42\%) and Methyl diisocyanate (Methylene diphenyl diisocyanate : MDI, NVC 100\%) resin were used for this experiments.

\subsection{Methods}

\subsubsection{Manufacture of Charcoal Board}

Charcoal board was manufactured with $15 \%$ of PVA (NVC $42 \%$ ), $5 \%$ of MDI (NVC $100 \%$ ) resin, and $100 \%$ of white charcoal powder as the dry weight basis. Final mat moisture content of charcoal board was $36 \%$, and 3 stage press cycle of $30-10-30 \mathrm{kgf} / \mathrm{cm}^{2}$ (1 min.-1 $\mathrm{min} .30$ sec.- 6 min.) was adapted to this mat. The dimensions of board was $20 \mathrm{~cm} \times 20 \mathrm{~cm} \times 1 \mathrm{~cm}$. This white charcoal board gave $0.58 \mathrm{~g} / \mathrm{cm}^{3}$ of density, $0 \%$ of thickness swelling, $43.96 \mathrm{kgf} / \mathrm{cm}^{2}$ of MOR, $8.5 \mathrm{kgf} / \mathrm{cm}^{2}$ of IB, and $92.9 \%$ of far-infrared emission (Lee et al., 2005).

\subsubsection{Overlay Process of Fancy Elm Veneer on Charcoal Board}

PVA resin was used for overlay of thin elm veneer on charcoal board. Two experiments for resin spread were carried out. One was for spread area variation of $30,50,70$, and $100 \%$ between charcoal board and fancy veneer with the standard spread of $120 \mathrm{~g} / \mathrm{m}^{2}$. The other was for non volatile content variation of $12.6,21$, and $42 \%$ with the standard spread of $120 \mathrm{~g} / \mathrm{m}^{2}$ and $100 \%$ spread area between charcoal board and fancy veneer. Hot pressing condition was $120^{\circ} \mathrm{C}$ of heating temperature, $90 \mathrm{sec}$. of heating time and $10 \mathrm{kgf} / \mathrm{cm}^{2}$ of pressure.

\subsubsection{Measurement of Gas Adsoprtion}

Gas adsoprtion of $\mathrm{C}_{2} \mathrm{H}_{2}$ was measured by Gas chromatograph (DC-14B, SHIMADZU Co.).

\subsubsection{Measurement of Porosity}




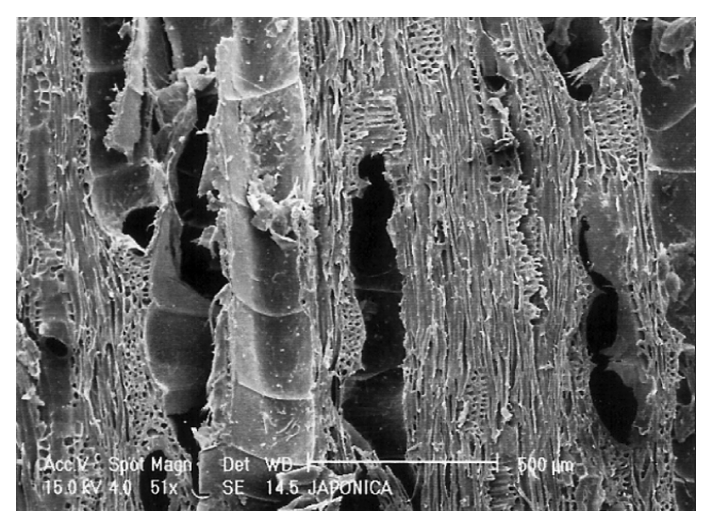

Fig. 1. Void of elm veneer (Radial section).

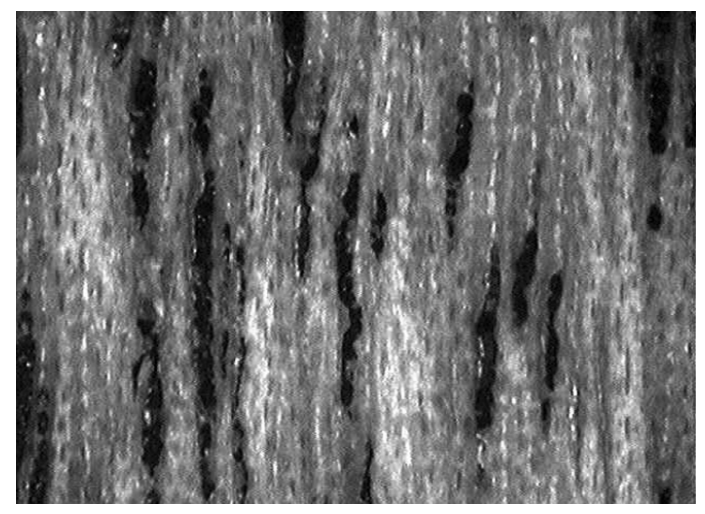

Fig. 2. Radial view of elm veneer by Optical video microscope $(\times 10)$.

Void ratio of thin veneer was calculated by Optical video microscope (Alphasystec, ICS305B).

\section{RESULTS and DISCUSSION}

\subsection{Void Ratio of Elm Veneer}

Fig. 1 showed the SEM picture of elm veneer of $0.22 \mathrm{~mm}$ thickness. Void ratio was $26.9 \%$ calculated by optical video microscope (Fig. 2). Void was derived from vessel elements because Elm is a ring porous hardwood. Outlines of ob-



Fig. 3. Fancy veneer overlaid charcoal board composites, Combination Example: Surface material: Elm veneer $0.22 \mathrm{~mm}$, Core material: Charcoal board, Back material: plywood $15 \mathrm{~mm}$ thickness.

jects were clear visible through the veneer. Fancy veneer overlaid charcoal board was shown in Fig. 3.

\subsection{Adsoprtion of Fancy Veneer Over- laid Charcoal Board}

\subsubsection{Adsoprtion along with Spread Area Variation}

Fancy veneer overlaid charcoal board was manufactured with PVA resin and the spread area of $30,50,70$, and $100 \%$ respectively. $100 \%$ spread area means the whole contact area between charcoal board and fancy veneer. 30\% means that only $30 \%$ of the area was appliedby the resin as a grid pattern, and $70 \%$ of area without resin. This experiment would examine how the loading of adhesive hinder the gas adsoprtion. Adsoprtion allowed from the surface of fancy veneer showed remaining concentration of measuring vessel, $1.8 \mathrm{ppm}$ of sole charcoal board without overlay, $2.04 \mathrm{ppm}$ of $30 \%$ spread area, $2.02 \mathrm{ppm}$ of $50 \%$ spread area, $2.05 \mathrm{ppm}$ of $70 \%$, and $2.03 \mathrm{ppm}$ of $100 \%$ respectively in Table 1. Therefore there was no difference of adsoprtion not only between sole charcoal board and fancy veneer overlaid charcoal boards with 
Adsoprtion Characteristic of Fancy Veneer Overlaid Charcoal Board Composite

Table 1. Ethylene gas adsorption along with the spreading area of adhesive and non volatile content of adhesive

\begin{tabular}{|c|c|c|c|c|c|c|c|c|c|c|}
\hline \multirow{2}{*}{$\begin{array}{l}\text { Time } \\
\text { (h) }\end{array}$} & \multirow{2}{*}{ Control $^{* 1}$} & \multicolumn{5}{|c|}{ Spreading area of adhesive ${ }^{* 2}$} & \multicolumn{4}{|c|}{ Non volatile content of PVA } \\
\hline & & $\mathrm{CON}$ & $30 \%$ & $50 \%$ & $70 \%$ & $100 \%$ & $\mathrm{CON}$ & $12.6 \%$ & $21 \%$ & $42 \%$ \\
\hline $\mathrm{O}$ & 17.35 & $13.52^{* 3}$ & 13.56 & 13.75 & 13.51 & 13.24 & 13.52 & 9.29 & 10.57 & 13.24 \\
\hline 3 & 16.73 & 3.95 & 4.02 & 3.88 & 3.87 & 4.05 & 3.95 & 4.22 & 4.59 & 4.05 \\
\hline 6 & 16.70 & 3.38 & 3.45 & 3.48 & 3.74 & 3.40 & 3.38 & 3.53 & 3.66 & 3.40 \\
\hline 12 & 16.59 & 2.59 & 2.6 & 2.64 & 2.41 & 2.39 & 2.59 & 2.68 & 2.87 & 2.39 \\
\hline 24 & 16.23 & 1.80 & 2.04 & 2.02 & 2.05 & 2.03 & 1.80 & 2.03 & 2.00 & 2.03 \\
\hline
\end{tabular}

*1 : ethylene gas concentration of blank vessel : ppm

*2 : Spreading area ratio of adhesive tototal veneer surface area : \%

*3 : remaining concentration of measuring vessel : ppm

spread area variations but also among fancy veneer overlaid charcoal boards with spread area variations.

\subsubsection{Adsoprtion along with Non Volatile Contents of Adhesive}

PVA emulsion resin as a wood adhesive has $42 \%$ of nonvolatile content in general. The glue line was thinned by the decreasing NVC. The lower the NVC was, the more the water content was. This experiment would examine how the glue lines cover the gas adsoprtion. Remaining concentration results of measuringvessel were indicated in Table 1, $2.03 \mathrm{ppm}$ of $12.6 \% \mathrm{NVC}$, $2.00 \mathrm{ppm}$ of $21 \% \mathrm{NVC}, 2.03 \mathrm{ppm}$ of $42 \%$ $\mathrm{NVC}$, and $1.8 \mathrm{ppm}$ of sole charcoal board without overlay. These results means there were no difference between the standard NVC and the diluted NVC.

\section{CONCLUSION}

This study showed that the spreading area and the nonvolatile content of adhesive did not affect the gas adsoprtion of fancy thin elm veneer overlaid charcoal board. Therefore, natural thin elm veneer overlaid charcoal board enhanced the aesthetic beauty, and it showed the same gas adsorption of charcoal board, which indicates that the natural thin elm veneer overlaid charcoal board could be used as a very useful indoor material for reducing the sick house problem.

\section{REFERENCES}

1. Jo, T. S., B. J. Ahn, and D. H. Choi. 2005. Changes of adsorption properties of woody charcoals prepared by different carbonizing temperatures. Mokchae Konghak 33(3): $45 \sim 52$.

2. Jo, T. S. et al. 2009. Changes of chemical bond in woody charcoal from different carbonization temperatures. Mokchae Konghak 37(1): 87 93.

3. Kim, B. R. and J. Y. Lee. 2006. Studies on utilization of bark by carbonization. Mokchae Konghak 34(1): $40 \sim 51$.

4. Kong, S. W. and B. R Kim. 2002. Adsorption characteristics of charcoals of major Koreanwood species and wood based materials. Mokchae Konghak 30(4): $33 \sim 40$.

5. Krzesinska M. and J. Zachariasz. 2007. Correlation between the carbonization temperature and the physical parameters of porous derived from Yucca flaccid. XIII International seminar on Physics and Chemistry of Solids. Journal of Physics: Confererence Series 79(2007)012012, IOP Publishing.

6. Lee, D. W. and B. R. Kim. 2002. Effect of car- 
bonized wastewoods on purification of wastewater. Mokchae Konghak 30(1): 34 39.

7. Lee, H. H., Y. M. Cho, and H. S. Park. 2005. Manufacture and properties of white charcoal board in relation with final mat moisture content and charcoal particle size. Mokchae Konghak 33(3): $22 \sim 29$.

8. Lee, H. H. et al. 2004. Development of charcoal containing new materials for produce packing, agricultural supplies, and building composies. Ministry of Agriculture and Forestry. p. 190.

9. Lee, H. H. et al. 2007. Manufacturing method of functional charcoal board laminate, Republic of Korea, Patent No. 10-0667371.

10. Lee, H. H., H. S. Park, and I. S. Seo. 2006. The manufacture of functional black charcoal board with excellent working properties from municipal wood waste. Republic of Korea, Patent No. 10-0587132.

11. Lee, H. H., Y. M. Cho, and H. S. Park. 2006. The manufacture of charcoal board and charcoal board composite with excellent properties such as dimensional safety, gas adsoprtion, and far-infra red emission for building interior material.
Republic of Korea, Patent No. 10-0572591.

12. Park, S. B., S. M. Lee, J. Y. Park, and S. H. Lee. 2009. Manufacture of Crack-free Carbonized Board from Fiberboard. Mokchae Konghak 37(4): $293 \sim 299$.

13. Rolland, J. L. 2006. The Food Encyclopedia: Over 8,000 Ingredients, Tools, Techniques and People. Robert Rose. p. 148. ISBN 0778801500.

14. Shin, C. S. and B. R. Kim. 2006. Effect of carbonized wastewoods on soil improvement (2). Mokchae Konghak. 34(6): $21 \sim 28$.

15. Shin, D. S. et al. 1983. Forest Products Chemistry. Hyungmoon Publishing Co. P. 458.

16. Wang, S. Y. C. P. 2003. Electromagnetic shielding efficiency of the electric field of charcoal from six wood species. Journal of wood science. Springer Japan 49(5): 450 454. 